\title{
Myocardial and Serum Galectin-3 Expression Dynamics Marks Post-Myocardial Infarction Cardiac Remodelling
}

Citation for published version (APA):

Sharma, U. C., Mosleh, W., Chaudhari, M. R., Katkar, R., Weil, B., Evelo, C., Cimato, T. R., Pokharel, S., Blankesteijn, W. M., \& Suzuki, G. (2017). Myocardial and Serum Galectin-3 Expression Dynamics Marks Post-Myocardial Infarction Cardiac Remodelling. Heart Lung and Circulation, 26(7), 736-745. https://doi.org/10.1016/j.hlc.2016.11.007

Document status and date:

Published: 01/07/2017

DOI:

10.1016/j.hlc.2016.11.007

Document Version:

Publisher's PDF, also known as Version of record

\section{Document license:}

Taverne

Please check the document version of this publication:

- A submitted manuscript is the version of the article upon submission and before peer-review. There can be important differences between the submitted version and the official published version of record.

People interested in the research are advised to contact the author for the final version of the publication, or visit the DOI to the publisher's website.

- The final author version and the galley proof are versions of the publication after peer review.

- The final published version features the final layout of the paper including the volume, issue and page numbers.

Link to publication

\footnotetext{
General rights rights.

- You may freely distribute the URL identifying the publication in the public portal. please follow below link for the End User Agreement:

www.umlib.nl/taverne-license

Take down policy

If you believe that this document breaches copyright please contact us at:

repository@maastrichtuniversity.nl

providing details and we will investigate your claim.
}

Copyright and moral rights for the publications made accessible in the public portal are retained by the authors and/or other copyright owners and it is a condition of accessing publications that users recognise and abide by the legal requirements associated with these

- Users may download and print one copy of any publication from the public portal for the purpose of private study or research.

- You may not further distribute the material or use it for any profit-making activity or commercial gain

If the publication is distributed under the terms of Article $25 \mathrm{fa}$ of the Dutch Copyright Act, indicated by the "Taverne" license above, 


\title{
Myocardial and Serum Galectin-3 Expression Dynamics Marks Post-Myocardial Infarction Cardiac Remodelling
}

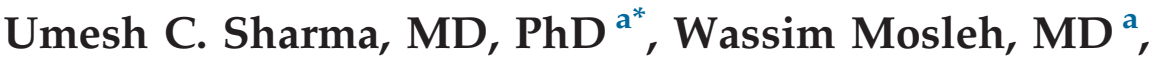 \\ Milind R. Chaudhari, MD, PhD ${ }^{a}$, Rujuta Katkar, MD $^{a}$, \\ Brian Weil, $\mathrm{PhD}^{\mathrm{a}}$, Chris Evelo, $\mathrm{PhD}^{\mathrm{b}}$, Thomas R. Cimato, $\mathrm{MD}, \mathrm{PhD}^{\mathrm{a}}$, \\ Saraswati Pokharel, MD, $\mathrm{PhD}^{\mathrm{c}}$, W. Matthijs Blankesteijn, $\mathrm{PhD}^{\mathrm{d}}$, \\ Gen Suzuki, MD, PhD ${ }^{\text {a }}$
}

${ }^{a}$ Division of Cardiovascular Medicine, University at Buffalo, Buffalo, NY, USA

${ }^{b}$ Department of Bioinformatics-BiGCaT, University of Maastricht, Maastricht, The Netherlands

${ }^{c}$ Department of Pathology and Oncology, Roswell Park Cancer Institute, Buffalo, NY, USA

${ }^{\mathrm{d}}$ Department of Pharmacology, University of Maastricht, Maastricht, The Netherlands

Received 13 May 2016; received in revised form 11 October 2016; accepted 13 November 2016; online published-ahead-of-print 19 December 2016

Background

Acute myocardial infarction (MI) causes significant changes in cardiac morphology and function. Galectin-3 is a novel and potentially therapeutically important mediator of cardiac remodelling. Myocardial and serum galectin-3 expression dynamics in response to the early cardiovascular outcomes after acute MI are not fully elucidated.

Methods

We first performed a comprehensive longitudinal microarray analyses in mice after acute MI. We then measured the serum levels of galectin-3 in a translational porcine model of coronary microembolisminduced post-ischaemic cardiac remodelling. We validated our pre-clinical studies in humans by measuring serum galectin-3 levels of 52 patients with acute ST-elevation MI (STEMI) and 11 healthy controls. We analysed galectin-3 data in relation to the development of major adverse cardiovascular outcomes (MACO).

Results Of the 9,753 genes profiled at infarcted and remote myocardium at eight different time points, dynamic myocardial overexpression of galectin-3 mRNA was detected. In a pig model of diffuse myocardial damage and cardiac remodelling, galectin-3 localised to the areas of tissue damage and myocardial fibrosis, with proportionate increase of their serum galectin-3 expression levels. In humans, increased serum galectin-3 level was associated with in-hospital MACO.

Conclusions In this translational study, we demonstrated that galectin-3 is dynamically overexpressed in response to acute MI-induced cardiac remodelling. Elevated galectin-3 levels are associated with the development of inhospital MACO.

Keywords

${ }^{*}$ Corresponding author at: Division of Cardiovascular Medicine, Clinical and Translation Research Center, 875 Ellicott Street, Suite 7030, Buffalo, New York 14203. Tel.: +716.829 .2663 ; fax: +716.854 .1840, Email: sharmau@buffalo.edu

(C) 2016 Australian and New Zealand Society of Cardiac and Thoracic Surgeons (ANZSCTS) and the Cardiac Society of Australia and New Zealand (CSANZ). Published by Elsevier B.V. All rights reserved. 


\section{Introduction}

Congestive heart failure (HF) leads to high morbidity and mortality [1]. The incidence of HF has increased recently due to better survival resulting from newly developed medical therapies and early revascularisation of acute coronary syndromes [2,3]. Early identification of the culprit mechanisms of cardiac remodelling and $\mathrm{HF}$ is a major research focus. Prior studies have reported elevated serum galectin-3 levels in patients with LV dysfunction resulted in poor outcomes after acute MI $[4,5,6,7,8,9]$. Several other population-based and clinical studies have implicated galectin-3 as a strong predictor of cardiovascular events [7-9].

After an acute MI, the myocardium hosts a complex neurohumoral and matricellular response. An abrupt tissue injury leads to loss of cardiomyocytes and surrounding microvasculature. The tissue necrosis is accompanied by a release of cellular byproducts including phospholipids. The loss of microvasculature also leads to altered local osmotic gradients leading to tissue oedema [10]. The vascular stasis and cellular chemotaxis is activated and an inflammatory response then ensues [11]. Concomitantly, a tissue reparative response is triggered, which leads to fibroblast proliferation and gradual deposition of myocardial matricellular proteins in lieu of the damaged cardiomyocytes [11-13].

Once the acute tissue injury is over, an adaptive remodelling is responsible for the maintenance of myocardial morphology and function $[12,14]$. The adapting ventricles often tend to dilate, whereas the lost cardiomyocytes are gradually replaced by cardiac fibroblasts and collagen fibres [15]. Overall, this dichotomy of tissue damage and repair ultimately determines the long-term outcomes related to ischaemic cardiomyopathy. A smaller infract size, early revascularisation and initiation of anti-remodelling therapy can have beneficial effects, whereas the opposite will lead to adverse remodelling and loss of cardiac function leading to $\mathrm{HF}$.

Several studies have examined the post-MI course in small and large translational animal models [14,16-18]. However, given the extended course of myocardial recovery, longitudinal genome-based studies have been difficult to perform on large animal models, and determination of the pathophysiological process of myocardial tissue injury, inflammation and repair has been difficult. Therefore, we have used a preclinical small animal model for the large-scale longitudinal genomics analysis. After the completion of the initial unbiased genomic profiling, we have performed additional hypothesis-driven studies on translational porcine models of $\mathrm{MI}$ for the validation of initial data on galectin-3 expression in relation to the development of cardiac dysfunction. Furthermore, in support of our preclinical translational findings, we have also conducted clinical studies to validate the association between elevated serum galectin-3 levels and early development of major adverse cardiovascular outcomes (MACO) in patients with acute ST-elevation myocardial infarction (STEMI).

\section{Methods}

\section{Murine Studies}

\section{Experimental MI}

We induced MI in 24 Swiss mice (age 10-12 weeks) using our study protocol described previously [19]. Briefly, xylazine (5 mg/kg s.c.) and ketamine ( $1 \mathrm{mg} / \mathrm{kg}$ i.m.) anaesthetised and intubated mice underwent a ligation (6-0 prolene) of the left anterior coronary artery. After a successful closure of chest wall with 5-0 silk sutures, mice were allowed to recover at $30{ }^{\circ} \mathrm{C}$. Sham surgeries were performed identically, except for the coronary artery ligation. Upon sacrifice, we isolated tissue RNA using an RNeasy Mini Kit (QIAGEN, Hilden, Germany). The Institutional Animal Care Committee of Maastricht University approved the procedure for care and treatment of animals. All procedures performed in the studies involving human participants were in accordance with the ethical standards of the institutional and/or national research committee and with the 1964 Helsinki declaration and its later amendments or comparable ethical standards.

\section{Microarrays}

We used the Incyte mouse GEM-2 cDNA libraries with 9,753 reporter genes for a microarray analysis (Incyte Genomics, Palo Alto, CA). Duplicate hybridisations were performed on these glass chips with pooled ( $N=3$, each group) mRNA samples obtained from acute infarct and remote myocardial regions. Since our primary question was to identify the temporal transcriptional profile following acute MI in the preclinical mouse model, we performed a comprehensive genomic profiling using multiple time points. We performed microarray analyses for a total of eight time-points so that a broad and comprehensive gene expression profiling in both infarct and remote myocardial segments could be identified. The early response to acute myocardial injury was examined at four distinct time-points (one day, two days, four days and seven days). The intermediate tissue repair and myocardial adaptive response was examined at two additional timepoints (14 days and 21 days). An additional two time-points (45 days and 90 days) were chosen to identify the chronic myocardial gene expression profile in response to postischaemic myocardial remodelling. For maximal accuracy, we only included those reporter spots in which at least $40 \%$ of pixels displayed fluorescence more than 2.5-times local background. The protocol for data mining and validation was adopted as detailed previously [20,21].

\section{Porcine Studies}

\section{Experimental MI}

We have previously generated representative porcine models of acute MI [22,23]. The coronary microembolisation model shows multiple, heterogeneous and patchy areas of myocardial scaring, and significant loss of myocardial function. In a study subset designed to examine galectin-3 expression dynamics, we generated acute MI in six Mini-swines 
(weight, 21-33 Kg) by infusing polystyrene microspheres (Polysciences, Inc. PA, USA). The microspheres were injected over five minutes under continuous ECG monitoring, as described previously [24]. Previous studies using this model have also demonstrated severe left ventricular dysfunction immediately following microsphere injection and persisting as long as three months, with patchy areas of infarction that typically amounted up to approximately $20 \%$ of LV mass [25]. The Institutional Animal Care Committee of University at Buffalo approved the procedure for care and treatment of animals.

\section{Two-Dimensional Echocardiography}

We performed 2D transthoracic echocardiography for the evaluation of LV systolic function, as previously described in pigs [26,27]. We obtained digitised images using a GE Vivid 7 sonography machine. The LV was imaged in the short-axis and long-axis projections from a right parasternal approach. Measurements were performed using the recent criteria reported by American Society of Echocardiography [28]. M-mode measurements of wall thickness were obtained to calculate regional functions. End-diastole was defined as the onset of the $\mathrm{R}$ wave and end-systole was taken as the minimal chamber dimension during ejection. Ejection fraction was used to assess global LV function.

\section{Serum Galectin-3 Measurements}

For galectin-3 serum measurements, we used a pre-coated galectin-3 specific 96-well strip microplate ELISA kit (RayBiotec, Norcross, GA). Galectin-3 immunoassays were performed in duplicate wells using pig serum samples obtained three months after the induction of acute MI. In this colourimetric quantitate sandwich ELISA, the measured optical densities were analysed with pre-determined standard galectin-3 concentrations according to the manufacturer's recommendations.

\section{Myocardial Galectin-3 Staining}

For myocardial galectin-3 detection, we performed immunohistochemistry using galectin-3 specific antibody (R\&D Systems). The $4 \mu \mathrm{m}$ formalin-fixed paraffin embedded tissues were incubated with an autostainer in a serum free protein block (Dako). Slides were then incubated for an hour with 1:1000 anti-galectin-3 antibody. Secondary antibody (JIRL) and rabbit envision labelled polymer Horseradish peroxidase anti-rabbit antibody (Dako) were then applied for 30 minutes. We used DAB substrate kit (Dako) for chromogen visualisation before counterstaining the slides with haematoxylin.

\section{Human Studies}

\section{Patient Selection}

At Gates Vascular Institute and Buffalo General Medical Center, informed consent was obtained from a total of 52 patients for participation in an observational study. The inclusion criteria consisted of patients who presented with a newly diagnosed ST-elevation myocardial infarction (STEMI) and underwent revascularisation by percutaneous intervention (PCI). Exclusion criteria included patients with documented history of trauma, MI or stroke within the preceding six months, or active malignancies in order to avoid any influences on circulating galectin-3 levels. Eleven healthy volunteers were recruited as controls for baseline galectin-3 levels. The study protocol was approved by the institutional review board of the University at Buffalo.

\section{Serum Galectin-3 Measurements}

Blood samples were collected within 12 to 48 hours from initial presentation for measurement of circulating galectin-3 levels. After centrifugation, samples were stored in heparinised test-tubes in refrigerators at $-80^{\circ} \mathrm{C}$ until galectin-3 assays were performed. For galectin-3 serum measurements, a pre-coated galectin-3 specific 96-well strip microplate ELISA kit (RayBiotec, Norcross, GA) was used and measured optical densities were analysed with predetermined standard galectin-3 concentrations according to the manufacturer's recommendations.

\section{Clinical Endpoints}

Baseline characteristics and in-hospital outcomes of all the patients were recorded by chart review. Comparisons between galectin-3 levels in study subjects and controls were performed and fold-increase in galectin-3 level from baseline (healthy controls) was calculated. The primary study endpoint was the composite outcome of early major adverse cardiovascular outcomes (MACO), which is defined as inhospital mortality, stroke, recurrent MI, or severely reduced left ventricular ejection fraction (LVEF) of $\leq 35 \%$ on ventriculogram performed at the time of revascularisation. Secondary endpoints included: (a) Severely reduced left ventricular ejection fraction (LVEF) of $\leq 35 \%$ on ventriculogram; (b) Elevated left ventricular end diastolic pressure (LVEDP) of $>20$ on ventriculogram; (c) Presence of diastolic dysfunction greater than stage 2 on echocardiogram; (d) Elevated E/E' ratio $\geq 15$ on echocardiogram; and (e) Atrial volume index $\geq 35$ on echocardiogram.

\section{Statistical Analysis}

For microarray studies, data are expressed as fold change over control in densitometric units. The microarray study design utilised a pooled tissue $(\mathrm{N}=3$, each time point, infarct and remote zones compared to sham group) to isolate the mRNAs and therefore, a weighted gene pool was presumed to be present during hybridisation. Paired group differences were compared with Student's T-test for normally distributed data. Mann-Whitney U-test was used to find difference between groups without normal distribution. Kruskal-Wallis test followed by Mann-Whitney U-test with Bonferroni correction was used to compare a) Normal vs LVEF <35\%; b) normal vs LVEF $>35 \%$; and c) LVEF $<35 \%$ vs $>35 \%$. Differences between categorical variables were analysed using Chisquare test or Fisher exact test as appropriate. Statistical data analysis was performed using SPSS software for Windows, version 23 (SPSS Inc., IL, USA). Differences between the groups were considered to be significant when $\mathrm{p}<0.05$. 


\section{Results}

\section{Post-MI Dynamic Overexpression of Galectin-3 mRNA in Murine Myocardium Compared to Natriuretic Peptide Precursor (NPP)}

The gene expression profile in post-MI groups has been presented as fold-change compared to the mice with Sham surgery. Comparison of galectin-3 expression dynamics with NPP showed early and rapid increase of NPP mRNA expression post-MI. Natriuretic peptide precursor expression peaked at two days, with its expression level reaching to the baseline levels at 90 days. Natriuretic peptide precursor is expressed in the heart in relation to myocardial stretch response. Compared to NPP, galectin-3 showed a relatively delayed overexpression profile with eight-fold overexpression at 14 days and six-fold overexpression at 21 days (Figure 1A). Unlike a robust overexpression of galectin-3 mRNA in the infarct region, minimal galectin-3 overexpression was noted in the remote myocardium (fold increase: $1.1,1$ day; $1.5,2$ days; $1.4,4$ days; $1.1,7$ days; $1.2,14$ days; 1.1 , 21 days; 1 , 45 days; and 1.3, 90 days), with highest overexpression (1.5fold) noted two days after acute MI.

\section{Concerted Overexpression of Galectin-3 With Other Genes Related to Cardiac Remodelling in Mice}

Cardiac remodelling involves complex and dynamic interactions between cardiomyocytes, fibroblasts, inflammatory cells and matricellular proteins $[29,30]$. We noted the stream of pathological changes progressing in a concerted pattern during post-ischaemic cardiac remodelling (Table 1). Of the 9,753 unique genes, we identified galectin- 3 as a dynamically expressed molecule in linearity with other genes crucial for myocardial remodelling. The most robustly expressed genes including cathepsin S, pro-collagen and macrophage expressed genes are already known to be crucial for the tissue scavenger and reparative response [21,30,31]. This temporal profiling of galectin-3 gene expression showed the majority of genes related to cardiac remodelling to peak at 14 days (Figure 1B), which, in fact, may represent a critical time point to initiate or maximise medical therapy. Also in line with current observations, we have previously shown galectin-3 to be a dynamic mediator of hypertension-induced cardiac remodelling, in which galectin-3 was a likely culprit molecule to induce cardiac fibroblast proliferation, collagen deposition and cardiac dysfunction [4,32].

\section{Increased Serum Galectin-3 Levels in a Porcine Model of Cardiac Dysfunction}

The Mini-pigs that underwent a coronary microembolism procedure showed significant cardiac remodelling and loss of cardiac function (Table 2). Compared to other porcine models of coronary ligation, coronary microembolism induces diffuse and patchy myocardial damage and leads to extensive alteration of myocardial morphology and function. In our quantitative enzymes-linked assays, we found a more than five-fold increase of serum galectin-3 levels in the postcoronary embolism model that also showed severely reduced LV systolic function (Figure $2 \mathrm{~A}$ and B). Serum galectin-3 was not detected in one sample, but in the remaining samples, analysis of linear trendline generated by the comparison of LV ejection fraction vs. serum galectin-3 showed a correlation co-efficient of 0.9485 . These findings are also supportive of our current state of clinical practice in which serum galectin-3

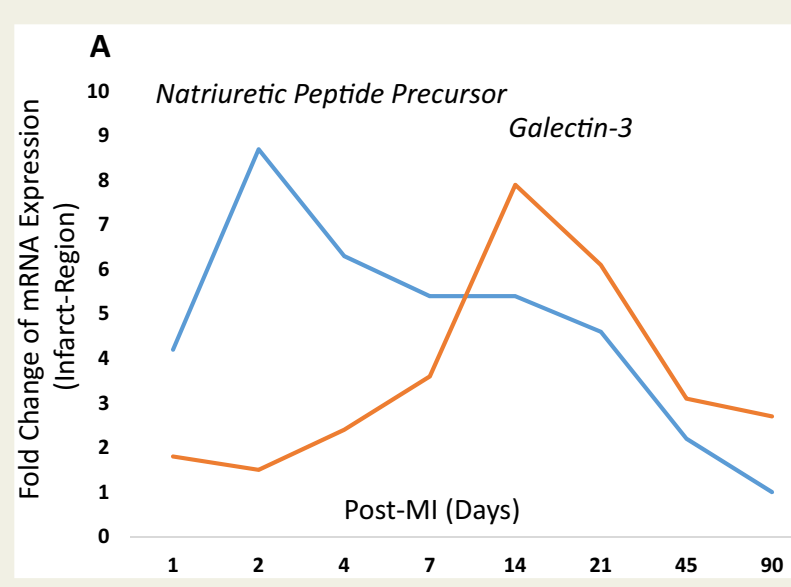

B

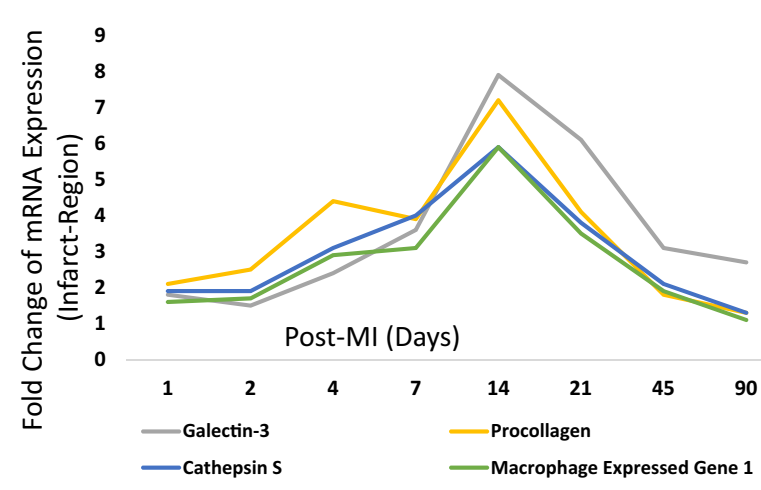

Figure 1 Temporal gene expression profile of five mRNAs (galectin-3, natriuretic peptide precursor, cathepsin $\mathrm{S}$, procollagen and macrophage expressed gene 1) that showed the most robust differential expression in infarct regions. The data columns represent fold-change of mRNA expression and rows represent the 8 time points chosen for genomic profiling after the induction of acute MI. Panel A represents the unique time points that show the peak expression of ANPP (2-days) and Galectin-3 (2-weeks). Panel B shows a concerted Galectin-3 expression profile that follows the expression dynamics of several others inflammatory and reparative genes associated with cardiac remodeling. 
Table 1 Temporal Expression Profile of 25 Most Robustly Overexpressed Genes after Acute Myocardial Infarction

\begin{tabular}{|c|c|c|c|c|c|c|c|c|}
\hline & 1 day & 2 days & 4 days & 7 days & 14 days & 21 days & 45 days & 90 days \\
\hline 1. Osteoblast specific factor 2 (fasciclin I-like) & 2.7 & 3.9 & 7.4 & 5 & 13.1 & 7.1 & 2.8 & 1.3 \\
\hline 2. Lysyl oxidase & 2.1 & 2.1 & 3.2 & 4.1 & 12.5 & 5.5 & 4.9 & 2 \\
\hline 3. Galectin-3 & 1.8 & 1.5 & 2.4 & 3.6 & 7.9 & 6.1 & 3.1 & 2.7 \\
\hline 4. Stromal cell derived factor 5 & 3.4 & 4.4 & 5.7 & 4.3 & 7.2 & 1.8 & 1.1 & 1 \\
\hline 5. Procollagen, type I, alpha 2 & 2.1 & 2.5 & 4.4 & 3.9 & 7.2 & 4.1 & 1.8 & -1.3 \\
\hline 6. Procollagen, type I, alpha 1 & 2.1 & 3.1 & 5.3 & 3.9 & 6.3 & 4.5 & 2.2 & 1 \\
\hline 7. Cathepsin S & 1.9 & 1.9 & 3.1 & 4 & 5.9 & 3.8 & 2.1 & 1.3 \\
\hline 8. Macrophage expressed gene 1 & 1.6 & 1.7 & 2.9 & 3.1 & 5.9 & 3.5 & 1.9 & 1.1 \\
\hline 9. Microfibrillar associated protein 5 & 2.2 & 2.5 & 4.4 & 4.2 & 5.4 & 3.8 & 2.9 & 1.6 \\
\hline 10. Natriuretic peptide precursor type A & 4.2 & 8.7 & 6.3 & 5.4 & 5.4 & 4.6 & 2.2 & 1 \\
\hline 11. Secreted acidic cysteine rich glycoprotein & 1.3 & 1.7 & 2.9 & 2.7 & 5 & 2.8 & 1.4 & 1.1 \\
\hline 12. Fibulin 5 & 1.7 & 1.8 & 2.4 & 2.5 & 4.9 & 1.6 & .3 & -1.7 \\
\hline 13. Thrombospondin 2 & 2.1 & 1.6 & 2.5 & 2.5 & 4.9 & 1.8 & 1.6 & 1.4 \\
\hline 14. CD68 antigen & 1.4 & 1.4 & 1.7 & 2 & 4.8 & 4.1 & 1.7 & 1.3 \\
\hline 15. Latent transforming growth factor beta binding protein 2 & 2.5 & 2.7 & 3 & 2.6 & 4.8 & 2.5 & 1.7 & 1.2 \\
\hline 16. Lysosomal-associated protein transmembrane 5 & 2 & 2.1 & 2.1 & 2.8 & 4.7 & 2.8 & 2 & 1.5 \\
\hline 17. ESTs, Weakly similar to rat cartilage oligometric protein & 1.6 & 1.4 & 2.7 & 2.6 & 4.7 & 2.1 & 2.7 & 2.2 \\
\hline 18. Lysyl oxidase-like protein & 2.3 & 2.7 & 3.3 & 2.7 & 4.6 & 3.3 & 2.3 & \\
\hline 19. ESTs, Highly similar to fibrinogen like protein & 2.1 & 2.3 & 3 & 2.8 & 4.6 & 2.4 & 1 & 1 \\
\hline 20. Biglycan & 2.3 & 2.7 & 3 & 3.2 & 4.6 & 2.7 & 1.6 & 1 \\
\hline 21. Procollagen, XIV, alpha 1 & 2 & 3.1 & 3.2 & 3.1 & 4.5 & 3 & 1.2 & -1.3 \\
\hline 22. Apolipoprotein E & 2.1 & 1.6 & 2.7 & 3.8 & 4.5 & 2.5 & 1 & -1.7 \\
\hline 23. Procollagen, type II, alpha 1 & 1.8 & 2.1 & 2.8 & 2.8 & 4.4 & 3.3 & 1.9 & -1 \\
\hline 24. Pigment epithelium-derived factor & 2.1 & 2.7 & 3.1 & 2.9 & 4.2 & 2.5 & 1.5 & 1 \\
\hline 25. Fibrillin 1 & 1.4 & 1.9 & 2.6 & 2.4 & 4.1 & 2.7 & 1.7 & 1.1 \\
\hline
\end{tabular}

Table 2 Echocardiographic Measurements to Examine Cardiac Morphology and Function in Pigs

\begin{tabular}{|c|c|c|c|c|c|}
\hline & $\mathbf{N}$ & $\begin{array}{l}\text { Infarct Region WT } \\
(\%)\end{array}$ & $\begin{array}{l}\text { Remote WT } \\
(\%)\end{array}$ & $\begin{array}{l}\text { FS } \\
(\%)\end{array}$ & $\begin{array}{l}\mathrm{EF} \\
(\%)\end{array}$ \\
\hline \multicolumn{6}{|l|}{ Normal } \\
\hline & 6 & $57 \pm 5$ & $95 \pm 5$ & $34 \pm 1$ & $64 \pm 1$ \\
\hline \multicolumn{6}{|l|}{ MI (3 Months) } \\
\hline & 6 & $36 \pm 6^{*}$ & $99 \pm 10$ & $18 \pm 2^{*}$ & $45 \pm 3.5^{*}$ \\
\hline
\end{tabular}

Values are presented as mean \pm SEM; ${ }^{*} \mathrm{p}<0.05$ vs. Normal; MI - Myocardial Infarction; WT - Wall Thickening; FS - Fractional Shortening; EF - Ejection Fraction

increase is associated with worse clinical outcomes, including rapid progression of HF and early mortality [33-35].

\section{Galectin-3 Co-Localisation to Damaged Myocardium in Pigs}

Immunohistochemistry showed strong galectin-3 positivity in the damaged myocardial segments. Consistent with our prior observations, the galectin-3 positive cells appeared large and vacuolated, which were previously confirmed to be macrophages by CD68 staining and in-situ hybridisation [4] (Figure 3A). These findings are also consistent with our previously reported experiments in which we showed macrophages as the source of galectin-3, whereas cardiac fibroblasts had perinuclear and cytoplasmic galectin-3 receptors [4]. The control hearts showed no evidence of myocardial damage or galectin-3 expression (Figure 3B).

\section{Increased Serum Galectin-3 Levels After Acute STEMI in Patients With Cardiac Dysfunction and Adverse Outcomes}

The results of pre-clinical study in the porcine model were validated in a clinical study. Demographic characteristics of study patients are illustrated in Table 3. STEMI patients developing MACO (MACO-positive) compared to without 

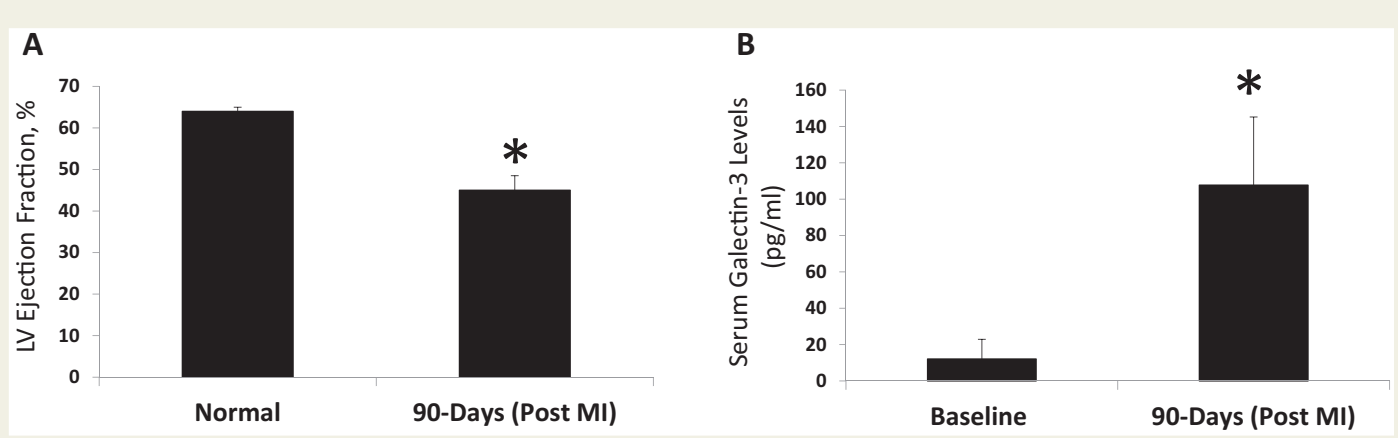

Figure 2 Comparison of left ventricular systolic function and serum levels of galectin-3 in normal and 90-days post-MI pigs. These pigs underwent coronary microembolisation procedure using polystyrene microsphere infusion for 5 minutes. LV systolic function was examined by transthoracic echocardiogram with a specialised large animal-specific ultrasound probe (panel A). The serum galectin-3 immunoassays were performed in our lab with a standard 96-well ELISA kit. Total serum concentrations were then quantified using pre-specified concentrations of recombinant galectin-3 to generate the standard curves (panel B). ${ }^{*}, \mathrm{p}<0.05$ compared to baseline measurements for both panels.

A

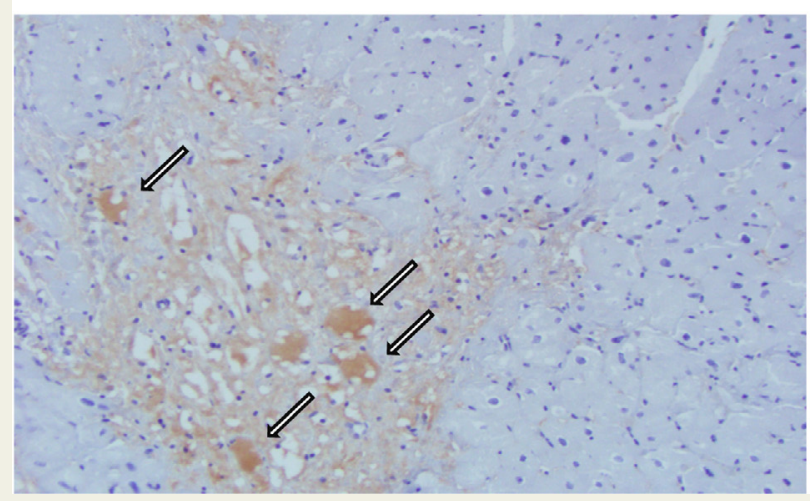

\section{B}

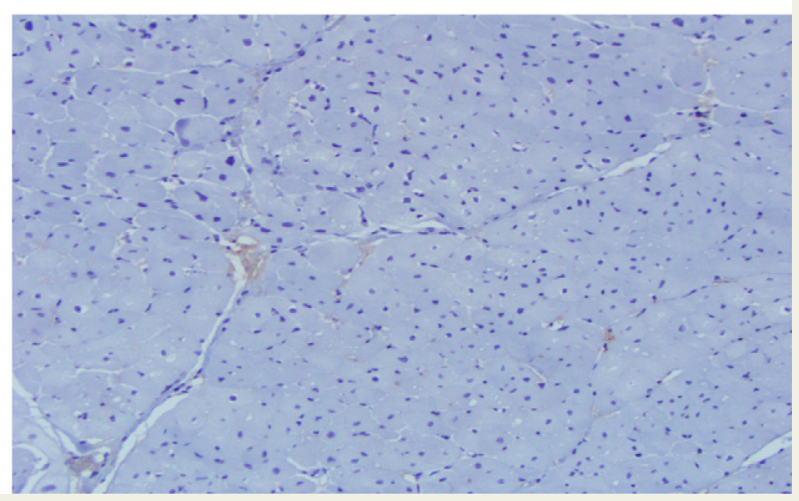

Figure 3 Immuno-histological demonstration of post-MI myocardial galectin-3 expression. A, a representative microscopic image of pig myocardium showing galectin-3 immunohistochemical staining. Galectin-3 staining is localised primarily to the areas of cardiomyocyte damage. Intense galectin-3 staining was visualised inside the large vacuolated cells (arrows) that were previously characterised by us as tissue macrophages. B, a representative image of galectin-3 immunohistochemical staining of a control pig myocardium. There is no myocyte damage, which correlates with the lack of galectin-3 staining (original magnifications 200x).

MACO (MACO-negative) were significantly older females, were more likely to have anterior MI on the ECG on presentation, and lower LVEF on in-hospital echocardiogram within 72-hours post-MI. Of the 52 STEMI patients, 43 patients had echocardiography performed during hospitalisation with only one patient having a prior documented history of HF. Of these patients, eight had severely reduced LV systolic function and showed a significant (2.96-fold) increase of serum galectin-3 concentrations, compared to controls $(\mathrm{p}<0.001)$. Using the assessment of LVEF obtained from the ventriculogram at the time of revascularisation, STEMI patients with severely reduced LV systolic function had a 3.57-fold increase of serum galectin-3 levels $(p<0.001)$, compared to a smaller 1.50-fold increase in STEMI patients without severely reduced LV systolic function $(\mathrm{p}<0.001)$. Comparison of serum galectin-3 levels between STEMI patients with severely reduced LV systolic function vs. STEMI patients without severely reduced LV systolic function (Figure 4A), showed a borderline significance $(p=0.055)$ and will need to be validated in a larger sample size. The association of elevated galectin-3 levels in relation to poor outcomes is elucidated by the results of the primary composite endpoint MACO (Figure 4B). MACO-positive patients had a significantly greater fold-increase in serum galectin-3 concentration than MACO-negative patients (5.05 \pm 1.67 vs. $1.34 \pm 0.21 ; \mathrm{p}<0.01)$. These findings indicate an association of elevated galectin-3 level with poor outcomes in STEMI patients, which may aid in identifying the subset of patients en route to the development of ischaemic cardiomyopathy as early targets for appropriate therapeutic interventions. Galectin-3 levels were not associated with elevated LVEDP on angiogram, elevated $\mathrm{E} / \mathrm{E}^{\prime}$ ratio or presence of diastolic 
Table 3 Demographic characteristics of all patients, and comparison between patients with MACO-positive* versus negative MACO-negative*

\begin{tabular}{|c|c|c|c|}
\hline Baseline Characteristics & $\begin{array}{l}\text { All patients } \\
(\mathrm{N}=52)\end{array}$ & $\begin{array}{l}\text { MACO-negative } \\
(n=43)\end{array}$ & $\begin{array}{l}\text { MACO-positive } \\
(n=9)\end{array}$ \\
\hline Age, yrs & $63.7 \pm 11.7$ & $61.7 \pm 1.7$ & $73.3 \pm 3.4^{*}$ \\
\hline Male gender, $\%$ & 59.6 & 65.1 & 33.3 \\
\hline Caucasian, $\%$ & 96.2 & 97.7 & 88.9 \\
\hline Prior MI, \% & 13.7 & 11.9 & 22.2 \\
\hline ASA use, $\%$ & 23.1 & 20.9 & 33.3 \\
\hline Statin use, $\%$ & 28.8 & 32.6 & 11.1 \\
\hline Beta blocker use, $\%$ & 25.0 & 23.3 & 33.3 \\
\hline ACEi use, $\%$ & 23.1 & 20.9 & 33.3 \\
\hline Diuretic use, $\%$ & 7.7 & 7.0 & 11.1 \\
\hline Peak troponin, $\mathrm{ng} / \mathrm{ml}$ & $81.51 \pm 14.73$ & $70.97 \pm 14.54$ & $131.89 \pm 48.00$ \\
\hline Anterior MI, \% & 32.7 & 25.6 & $66.7^{*}$ \\
\hline LVEDP, mmHg & $21.6 \pm 1.6$ & $21.3 \pm 1.7$ & $24.2 \pm 4.6$ \\
\hline LVEF (Echo-based) after MI & $47.6 \pm 1.8$ & $50.3 \pm 1.8$ & $37.8 \pm 4.3^{*}$ \\
\hline Serum galectin-3, fold increase compared to controls & $1.98 \pm 0.38$ & $1.34 \pm 0.21$ & $5.05 \pm 1.67^{*}$ \\
\hline
\end{tabular}

Results are expressed as percentage, or Mean \pm SEM. *p $<0.05$ vs MACO-negative.

MACO: Major adverse cardiac outcomes. MACOs are defined as composite endpoint of all-cause mortality, recurrent MI, stroke, and severely reduced LVEF of $\leq 35 \%$ on ventriculogram. MI - myocardial infarction; ASA - aspirin; ACEi - angiotensin converting enzyme inhibitor; and LVEDP - left ventricular end diastolic pressure.
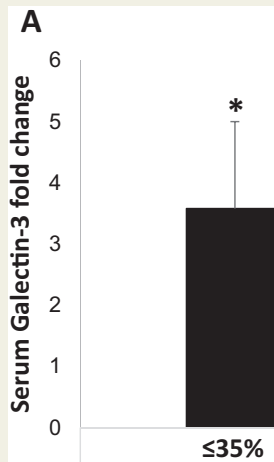

LVEF on ventriculogram
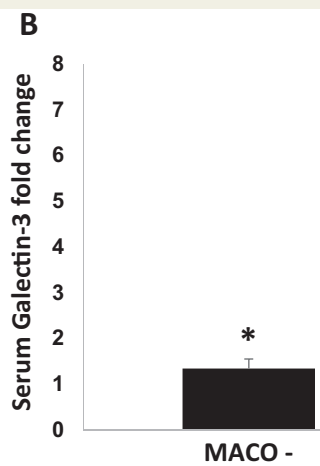

Figure 4 Comparison of fold changes in serum galectin-3 level in patients with LVEF $\leq 35 \%$ and $>35 \%$ on ventriculogram (Panel A) and in MACO - and MACO + patients (Panel B). The serum galectin-3 immunoassays were performed in our lab with a standard 96-well ELISA kit. The fold change in serum galectin-3 level is from its baseline, i.e. compared to healthy control. Data are expressed as Mean \pm standard error of mean (SEM). *, p $<0.05$ compared to control group; \#, $<<0.05$ compared to MACO- group in Panel B.

dysfunction greater than stage 1 on echocardiogram, however were associated with high atrial volume index (Table 4).

\section{Discussion}

The increasing prevalence of ischaemic cardiomyopathy represents a major health problem; thus finding possible new approaches to its early identification and treatment are of great significance. Although galectin-3 has developed rapidly from the bench to bedside as a biomarker, the dynamic of galectin-3 expression in relation to other mediators of cardiac remodelling required further study. In this study, we have examined that galectin-3 is not only a marker on itself but also shows a concerted relationship with other inflammatory and myocardial matricellular genes dynamically overexpressed in relation to acute MI. In patients with acute MI, serum galectin-3 overexpression is associated with major adverse cardiovascular outcomes.

Our largest-to-date and comprehensive temporal gene expression profile has provided important and previously 
Table 4 Comparison of echocardiographic $(<72 \mathrm{~h})$ and angiographic diastolic parameters in patients in relation to galectin-3 levels

\begin{tabular}{|c|c|c|c|}
\hline Early outcomes & & $(\mathrm{N})$ & $\begin{array}{l}\text { Fold increase of galectin-3 from baseline } \\
\text { (compared to controls) }\end{array}$ \\
\hline \multirow{2}{*}{ LVEDP } & $\leq 20 \mathrm{mmHg}$ & $(25)$ & $1.44 \pm 0.29$ \\
\hline & $>20 \mathrm{mmHg}$ & $(10)$ & $2.32 \pm 0.83$ \\
\hline \multirow[t]{2}{*}{ Diastolic dysfunction } & $\leq$ stage I & (39) & $1.57 \pm 0.32$ \\
\hline & $>$ stage I & (5) & $2.59 \pm 1.49$ \\
\hline \multirow[t]{2}{*}{ Atrial volume index } & $\leq 35$ & (26) & $1.06 \pm 0.23$ \\
\hline & $>35$ & (5) & $3.32 \pm 1.14^{*}$ \\
\hline \multirow[t]{2}{*}{$\mathrm{E} / \mathrm{E}^{\prime}$ ratio } & $<15$ & $(30)$ & $1.56 \pm 0.37$ \\
\hline & $\geq 15$ & $(10)$ & $2.22 \pm 0.94$ \\
\hline
\end{tabular}

Results are expressed as Mean \pm SEM. * ${ }^{*}<0.05$.

LVEDP - left ventricular end diastolic pressure; and E/E' ratio - ratio of mitral peak velocity of early filling to early diastolic mitral annular velocity.

unknown expression dynamics of galectin-3. With a similar genomic strategy, we had previously identified galectin-3 as a novel mediator of $\mathrm{HF}$ and its downregulation following therapy with angiotensin receptor antagonists in a hypertensive rat model $[4,21]$. Galectin-3 was then found to be overexpressed in the myocardium of the rodents en route to the development of HF. Many other clinical studies, including the Framingham Heart Study, later expanded the utility of galectin-3 as a biomarker for cardiac remodelling, fibrosis, and early mortality due to HF exacerbation and recurrent hospitalisations [5,17,33,36-38]. Our pre-clinical studies in an angiotensin-II overexpression model have also shown galectin-3 as a possible early mediator of cardiac dysfunction and subsequent HF [4]. The current study expands our previous discovery to the next level as galectin-3 shows a robust and dynamic myocardial expression after acute MI.

It is noteworthy that gene-expressions are not always translated to post-transcriptional protein synthesis. However, our prior microarray study with the similar array platform allowed us to validate these genes by real-time PCR, Western blotting, immunohistochemistry and functional studies [4]. After identifying increased galectin-3 gene expression in the infarct region, we have validated these findings at tissue and serum levels using a translational porcine model of acute MI. More specifically, a porcine model of coronary micro-embolism shows acute myocardial injury followed by rapid LV remodelling and loss of cardiac function [25]. We decided to re-examine the LV function and serum galectin-3 levels in these pigs after three moths postMI, a time-point that is often used in a clinical set up to discern treatment responsiveness.

Unlike other clinical biomarkers, it is known that galectin-3 has pro-fibrotic activity and can lead to loss of cardiac function [4]. Cardiac fibroblasts have abundant intracytoplasmic and perinuclear galectin-3 receptors. Intrapericardial infusion of galectin-3 leads to LV dysfunction and excess collagen I deposition [4]. Since the functional dynamics of galectin-3 were characterised in our prior studies, both in vitro and in vivo, it is important to recognise that sustained myocardial and peripheral galectin-3 increase in response to acute MI can be a culprit mechanism during the transition from compensated state to $\mathrm{HF}$.

While the remote zone in an acute $\mathrm{MI}$ is not directly injured by the infarction, it is exposed to increased wall tension and abnormal shear forces following the infarction and, in mice, decompensates within weeks [14]. Unlike the dynamic changes noted in the infarct region, only a minimal increase of galectin-3 expression (maximum increase: 1.5-fold, two days post MI) was noted in the remote segments. There were multiple genes that showed increased expression in the infarct region or similarly in infarct and remote regions, but none were completely unique to the remote regions.

Taken together, this large, comprehensive microarray study and its translational validation have provided insights into several important aspects of post-infarct cardiac remodelling. Galectin-3 is highly overexpressed in the infarct regions after acute MI. The natriuretic peptide, a commonly used HF biomarker, also shows a similar dynamic expression but peaks at a much earlier time point (two days). Interestingly, galectin-3 gene expression dynamics closely follow the expression of other molecules responsible for myocardial remodelling. Furthermore, increased serum and myocardial galectin-3 protein levels were noted in a translational preclinical model of coronary microembolism-induced acute myocardial injury. Additionally, the association of serum galectin-3 levels with severely reduced LV function and poor cardiovascular outcomes has been validated in the clinical setting through our clinical study. The difference between this study and prior clinical studies is that, while the prognostic role of galectin-3 has been previously demonstrated in patients with ACS $[7,8,9]$, our study is the first to-date to also demonstrate the association between galectin-3 levels and poor cardiovascular outcomes as early as in-hospital outcomes. This is important as translational studies on porcine models have demonstrated that severe LV dysfunction immediately following microsphere injection has persisted 
as long as three months [25]. The association between galectin-3 levels and early LV dysfunction, hours after STEMI, makes it a possible very-early biomarker predicting longterm ischaemic cardiomyopathy, though longitudinal prospective studies are indicated to support this concept.

Finally, this study has advanced our prior discoveries and helped bridge translation gaps on the role of galectin-3 expression en route to cardiac remodelling. The implications of these studies are: a) Galectin-3 is a novel marker and a likely mediator of post-infarct cardiac remodelling; b) Concerted expression of galectin-3 and other mediators at two weeks implicates one to two weeks post MI as a meaningful time-point to initiate or optimise medical therapy. Further studies are required to further examine the causative and possibly a mechanistic role of galectin- 3 to mediate postinfarct cardiac remodelling and loss of cardiac function.

\section{Competing Interests}

None

\section{Acknowledgements}

Research reported in this publication was supported by the National Center for Advancing Translational Sciences of the National Institutes of Health under award number UL1TR001412 to the University at Buffalo. The content is solely the responsibility of the authors and does not necessarily represent the official views of the NIH. This study was supported by ZonMW grant (917.36.320) to Dr. WM Blankesteijn.

\section{References}

[1] Gajanana D, Shah M, Junpapart P, Romero-Corral A, Figueredo VM, Bozorgnia B. Mortality in systolic heart failure revisited: Ischemic versus non-ischemic cardiomyopathy. International Journal of Cardiology 2016;224:15-7.

[2] Guidry UC, Evans JC, Larson MG, Wilson PW, Murabito JM, Levy D. Temporal trends in event rates after Q-wave myocardial infarction: the Framingham Heart Study. Circulation 1999;100:2054-9.

[3] Steg PG, Dabbous OH, Feldman LJ, Cohen-Solal A, Aumont MC, LopezSendon J, et al. and Global Registry of Acute Coronary Events I. Determinants and prognostic impact of heart failure complicating acute coronary syndromes: observations from the Global Registry of Acute Coronary Events (GRACE). Circulation 2004;109:494-9.

[4] Sharma UC, Pokharel S, van Brakel TJ, van Berlo JH, Cleutjens JP, Schroen B, et al. Galectin-3 marks activated macrophages in failure-prone hypertrophied hearts and contributes to cardiac dysfunction. Circulation 2004;110:3121-8.

[5] Ho JE, Liu C, Lyass A, Courchesne P, Pencina MJ, Vasan RS, et al. Galectin-3, a marker of cardiac fibrosis, predicts incident heart failure in the community. J Am Coll Cardiol 2012;60:1249-56.

[6] Daniels LB, Clopton P, Laughlin GA, Maisel AS, Barrett-Connor E. Galectin-3 is independently associated with cardiovascular mortality in community-dwelling older adults without known cardiovascular disease: The Rancho Bernardo Study. Am Heart J 2014;167. 674-82 e1.

[7] Maiolino G, Rossitto G, Pedon L, Cesari M, Frigo AC, Azzolini M, et al. Galectin-3 predicts long-term cardiovascular death in high-risk patients with coronary artery disease. Arterioscler Thromb Vasc Biol 2015;35: 725-32.

[8] Tsai TH, Sung PH, Chang LT, Sun CK, Yeh KH, Chung SY, et al. Value and level of galectin-3 in acute myocardial infarction patients undergoing primary percutaneous coronary intervention. J Atheroscler Thromb 2012;19:1073-82

[9] Grandin EW, Jarolim P, Murphy SA, Ritterova L, Cannon CP, Braunwald E, et al. Galectin-3 and the development of heart failure after acute coronary syndrome: pilot experience from PROVE IT-TIMI 22. Clin Chem 2012;58:267-73.

[10] Buja LM, Entman ML. Modes of myocardial cell injury and cell death in ischemic heart disease. Circulation 1998;98:1355-7.

[11] Cleutjens JP, Blankesteijn WM, Daemen MJ, Smits JF. The infarcted myocardium: simply dead tissue, or a lively target for therapeutic interventions. Cardiovascular Research 1999;44:232-41.

[12] Cleutjens JP, Verluyten MJ, Smiths JF, Daemen MJ. Collagen remodeling after myocardial infarction in the rat heart. The American Journal of Pathology 1995; 147:325-38.

[13] Daskalopoulos EP, Janssen BJ, Blankesteijn WM. Myofibroblasts in the infarct area: concepts and challenges. Microscopy and Microanalysis: the official journal of Microscopy Society of America, Microbeam Analysis Society, Microscopical Society of Canada 2012;18:35-49.

[14] Yang F, Liu YH, Yang XP, Xu J, Kapke A, Carretero OA. Myocardial infarction and cardiac remodelling in mice. Exp Physiol 2002;87:547-55.

[15] Weber KT, Sun Y, Diez J. Fibrosis: a living tissue and the infarcted heart. Journal of the American College of Cardiology 2008;52:2029-31.

[16] Andreka G, Vertesaljai M, Szantho G, Font G, Piroth Z, Fontos G, et al Remote ischaemic postconditioning protects the heart during acute myocardial infarction in pigs. Heart 2007;93:749-52.

[17] Sanchez-Mas J, Lax A, Asensio-Lopez MC, Fernandez-Del Palacio MJ, Caballero L, et al. Galectin-3 expression in cardiac remodeling after myocardial infarction. International Journal of Cardiology 2014;172:e98-e101.

[18] Gonzalez GE, Cassaglia P, Noli Truant S, Fernandez MM, Wilensky L, Volberg V, et al. Galectin-3 is essential for early wound healing and ventricular remodeling after myocardial infarction in mice. International Journal of Cardiology 2014;176:1423-5.

[19] Aartsen WM, Schuijt MP, Danser AH, Daemen MJ, Smits JF. The role of locally expressed angiotensin converting enzyme in cardiac remodeling after myocardial infarction in mice. Cardiovascular Research 2002;56: 205-13.

[20] Bandman O, Coleman RT, Loring JF, Seilhamer JJ, Cocks BG. Complexity of inflammatory responses in endothelial cells and vascular smooth muscle cells determined by microarray analysis. Annals of the New York Academy of Sciences 2002;975:77-90.

[21] Schroen B, Heymans S, Sharma U, Blankesteijn WM, Pokharel S, Cleutjens JP, et al. Thrombospondin-2 is essential for myocardial matrix integrity: increased expression identifies failure-prone cardiac hypertrophy. Circ Res 2004;95:515-22.

[22] Canty Jr JM, Suzuki G. Myocardial perfusion and contraction in acute ischemia and chronic ischemic heart disease. Journal of Molecular and Cellular Cardiology 2012;52:822-31.

[23] Canty Jr JM, Suzuki G. Heterogeneity of apoptosis and myolysis in coronary microembolization: a competition between programmed cell death and programmed cell survival. European Heart Journal 2002;23:838-40.

[24] Skyschally A, Leineweber K, Gres P, Haude M, Erbel R, Heusch G. Coronary microembolization. Basic Research in Cardiology 2006;101: 373-82.

[25] Heusch G, Kleinbongard P, Bose D, Levkau B, Haude M, Schulz R, et al. Coronary microembolization: from bedside to bench and back to bedside. Circulation 2009;120:1822-36.

[26] Malm BJ, Suzuki G, Canty JM, Fallavollita JA. Variability of contractile reserve in hibernating myocardium: dependence on the method of inotropic stimulation. Cardiovascular Research 2002;56:422-32.

[27] Suzuki G, Weil BR, Leiker MM, Ribbeck AE, Young RF, Cimato TR, et al Global intracoronary infusion of allogeneic cardiosphere-derived cells improves ventricular function and stimulates endogenous myocyte regeneration throughout the heart in swine with hibernating myocardium. PloS One 2014;9:e113009.

[28] Lang RM, Badano LP, Mor-Avi V, Afilalo J, Armstrong A, Ernande L, et al. Recommendations for cardiac chamber quantification by echocardiography in adults: an update from the American Society of Echocardiography and the European Association of Cardiovascular Imaging. European Heart Journal Cardiovascular Imaging 2015;16:233-70.

[29] Sharma UC, Pokharel S, Evelo CT, Maessen JG. A systematic review of large scale and heterogeneous gene array data in heart failure. Journal of Molecular and Cellular Cardiology 2005;38:425-32.

[30] Weinberger T, Schulz C. Myocardial infarction: a critical role of macrophages in cardiac remodeling. Frontiers in Physiology 2015;6:107.

[31] Cheng XW, Obata K, Kuzuya M, Izawa H, Nakamura K, Asai E, et al Elastolytic cathepsin induction/activation system exists in myocardium 
and is upregulated in hypertensive heart failure. Hypertension 2006; 48:979-87.

[32] Liu YH, D'Ambrosio M, Liao TD, Peng H, Rhaleb NE, Sharma U, et al. $\mathrm{N}$-acetyl-seryl-aspartyl-lysyl-proline prevents cardiac remodeling and dysfunction induced by galectin-3, a mammalian adhesion/growthregulatory lectin. American Journal of Physiology Heart and Circulatory Physiology 2009;296:H404-12.

[33] van Kimmenade RR, Januzzi Jr JL, Ellinor PT, Sharma UC, Bakker JA, Low $\mathrm{AF}$, et al. Utility of amino-terminal pro-brain natriuretic peptide, galectin-3, and apelin for the evaluation of patients with acute heart failure. J Am Coll Cardiol 2006;48:1217-24.

[34] Shah RV, Chen-Tournoux AA, Picard MH, van Kimmenade RR, Januzzi JL. Galectin-3, cardiac structure and function, and long-term mortality in patients with acutely decompensated heart failure. European Journal of Heart Failure 2010;12:826-32.
[35] Edelmann F, Holzendorf V, Wachter R, Nolte K, Schmidt AG, KraigherKrainer E, et al. Galectin-3 in patients with heart failure with preserved ejection fraction: results from the Aldo-DHF trial. European Journal of Heart Failure 2015;17:214-23.

[36] Hrynchyshyn N, Jourdain P, Desnos M, Diebold B, Funck F. Galectin-3: a new biomarker for the diagnosis, analysis and prognosis of acute and chronic heart failure. Archives of Cardiovascular Diseases 2013;106:541-6.

[37] Lax A, Sanchez-Mas J, Asensio-Lopez MC, Fernandez-Del Palacio MJ, Caballero L, Garrido IP, et al. Mineralocorticoid receptor antagonists modulate galectin-3 and interleukin-33/ST2 signaling in left ventricular systolic dysfunction after acute myocardial infarction. JACC Heart Failure 2015;3:50-8

[38] Weir RA, Petrie CJ, Murphy CA, Clements S, Steedman T, Miller AM, et al. Galectin-3 and cardiac function in survivors of acute myocardial infarction. Circ Heart Fail 2013;6:492-8. 